\title{
Perinatal and neonatal outcomes of pregestational diabetes mellitus: a retrospective study
}

Giampiero Capobianco ( $\nabla$ capobia@uniss.it)

University of Sassari

Alessandra Gulotta

University of Sassari

Giulio Tupponi

University of Sassari

Francesco Dessole

University of Sassari

Giuseppe Virdis

University of Sassari

Claudio Cherchi

Bambino Gesù Children's Hospital, IRCCS

Davide Vita

University of Sassari

Marco Petrillo

University of Sassari

Giorgio Olzai

Sassari University

Roberto Antonucci

Sassari University

Laura Saderi

University of Sassari

Pier Luigi Cherchi

University of Sassari

Salvatore Dessole

University of Sassari

Giovanni Sotgiu

University of Sassari

Research Article 
Keywords: Gestational Pregestational diabetes mellitus (PGDM), Type 1 Diabetes Mellitus (DM1), Type 2 Diabetes Mellitus (DM2), maturity onset diabetes of the young (MODY), foetal outcomes, neonatal outcomes

Posted Date: May 25th, 2021

DOl: https://doi.org/10.21203/rs.3.rs-555135/v1

License: (c) (1) This work is licensed under a Creative Commons Attribution 4.0 International License. Read Full License 


\section{Abstract}

\section{Background}

The aim of the study was to evaluate maternal-foetal and neonatal clinical outcomes in a group of patients with pregestational diabetes mellitus (PGDM) such as diabetes mellitus type 1 (DM1), diabetes mellitus type 2 (DM2), and maturity onset diabetes of the young (MODY).

\section{Methods}

Overall, 174 pregnant women, nulliparous and multiparous, with single pregnancy were enrolled. The selected patients were divided into two groups: PGDM (42 with DM1, 14 with DM2, and 2 with MODY); 116 patients with a negative pathological history of diabetes mellitus were the control.

Results

We reported an incidence of preterm delivery of $55.2 \%$ in the PGDM group, of $59.5 \%$ in the DM1 group, and $42.9 \%$ in the DM2 group VS. $6 \%$ in the controls. Foetal growth disorders, such as intrauterine growth retardation, small for gestational age, and foetal macrosomia were found in $19 \%$ and $3.6 \%$ in the case and in the control group, respectively. A relationship between DM2 and gestational hypertension was found.

\section{Conclusions}

patients with PGDM are at increased risk of perinatal and neonatal complications in comparison with pregnant women without PGDM.

\section{Background}

The prevalence of diabetes mellitus in pregnancy is increasing worldwide in parallel with that of obesity. Gestational Diabetes Mellitus (GDM) is diagnosed in the majority of the cases, followed by pregestational diabetes (PGDM), such as Diabetes Mellitus type 1 (DM1) and type 2 (DM2) [1].

The Italian region Sardinia has an incidence rate of DM1 equal to 33.4 per 100,000, which is the second highest globally [2]. Pre-gestational diabetes is associated with adverse neonatal outcomes [3].

The incidence of adverse maternal outcomes is high in case of PGDM [4-8]: abortions and low birth weight $(<2,500$ grams) were more common, as well as congenital anomalies. Notably, the types and patterns of congenital malformations associated with maternal PGDM are non-random [9], with an increased risk of heart, central nervous system, and skeleton malformations.

The aim of the present study was to evaluate maternal-fetal and neonatal clinical outcomes of a cohort of patients with PGDM (DM1, DM2, and maturity onset diabetes of the young -MODY-) in comparison with those of pregnant individuals without diabetes. 


\section{Methods}

A retrospective longitudinal study was carried out: patients aged 18 and 44 years were enrolled between January 2016 and August 2020. They were followed-up in a tertiary care Italian hospital.

A formal ethical approval was not needed according to the Italian law on observational studies.

Selected patients were divided into two groups: PGDM and control (negative pathological history of DM and with a negative oral glucose test tolerance -OGTT- performed at 24-28 weeks of gestation) [10-11].

The two groups were homogeneous by age (calculated at the time of delivery), with a ratio of 1: 2 .

The criteria for the diagnosis of diabetes included a fasting plasma glucose (FPG) levels $\geq 126 \mathrm{mg} / \mathrm{dl}$ (7.0 mmol/l) and 2-h plasma glucose (PG) level $\geq 200 \mathrm{mg} / \mathrm{dl}(11.1 \mathrm{mmol} / \mathrm{l})$ during an OGTT.

Characteristics of pregnancy and delivery were collected at the hospital admission and at delivery; Neonatal data were retrieved from the admission registries and from the medical records of newborns admitted to the neonatal intensive care unit (NICU). The following data were collected: age, parity, height, pregravidic weight, weight at delivery, last menstruation, comorbidity (cardiovascular diseases, thyroid diseases, multiple sclerosis, and other autoimmune diseases), prenatal screening surveys (e.g., combined test, noninvasive prenatal test, villocentesis, amniocentesis, and fetal echocardiography).

The variables collected for each group of women were summarized in the following categories: pregnancy outcomes, diseases of pregnancy and fetal pathologies, and neonatal outcomes. The following pregnancy outcomes were collected: gestational age at childbirth (GA); hospital stay; mode of delivery (spontaneous vaginal delivery or caesarean section). Diseases of pregnancy and foetal pathologies: Threatened abortion; Threatened preterm birth; Gestational hypertension; Preeclampsia and HELLP syndrome; Placental abruption; Pathology of amniotic fluid (oligohydramnios and polydramnios); Premature rupture of membranes (PROM) and preterm rupture of membranes (P-PROM); Macrosomia; Intrauterine growth retardation (IUGR) foetus; Morphological abnormalities diagnosed on ultrasound. Neonatal outcomes: Weight at birth compared to those expected for the gestational age (in percentiles), and then classification within one of the classes of Appropriate for Gestational Age (AGA), Small for Gestational Age (SGA), or Large for Gestational Age (LGA). For this study we used the definition of the Royal College of Obstetricians and Gynaecologists (RCOG) [12] which informs UK clinical practice, based on sonographic estimated fetal weight (EFW) measurement $<10$ th percentile to describe a fetus that has not reached its target weight. Patients were divided in three groups for comparison; fetuses with EFW below the 10th percentile for gestational age (SGA), fetuses with EFW $>10$ th percentile for gestation (AGA) and fetuses > 90th percentile for gestation (LGA) according to the Alexander growth standard [13]; Apgar at the first minute; Number of hospitalization days and at which intensity of care (nursery, neonatology or NICU); Recognition of respiratory diseases at birth such as Respiratory Distress Syndrome (RDS), transient tachycardia of the newborn (TTN) or apnea crisis, and if there has been any intubation; 
Blood glucose at the third hour; Hypoglycemia status and glucose supplementation; Neonatal jaundice, treated or not with phototherapy; Morphological abnormalities found at birth.

An ad hoc electronic database was created to collect all study variables. Qualitative data are summarized with absolute and relative (percentage) frequencies. Medians and interquartile ranges were used for quantitative variables with a non-parametric distribution. Chi-squared or Fisher exact test was used to compare qualitative variables for individuals with and without diabetes, whereas Mann-Whitney test to compare non-normal quantitative variables. Logistic regression analysis was performed to assess the relationship between pregnancy and fetal characteristics and diabetes. A two-tailed $p$-value $<0.05$ was considered statistically significant. Statistical software STATA version 16 (StataCorp, Texas, USA) was adopted for all statistical analyses.

\section{Results}

A total of 58 PGDM patients were recruited, with 42 diagnosed with DM1, 14 with DM2, and 2 with MODY. 116 patients had a negative pathological history of diabetes mellitus (control group)

A higher median (IQR) pre-gestational body weight [61 (55.5-72.5) VS. 57 (50.5-63); p-value: 0.003] and BMI [23.7 (20.8-28) VS. 22 (19.8-24); p-value: 0.005] were found in the PGDM group (Table 1).

Furthermore, the prevalence of obesity was significantly higher among the cases (16.7\% VS. $2.6 \%$; $p$-value 0.001).

Similarly, a higher median (IQR) body weight [74 (65-85) VS. 70 (63-75); p-value: 0.01] and BMI [27.9 (25.7-32.2) VS. 26.6 (24.8-28.8); p-value: 0.02$]$ were recorded at the time of delivery.

A history of multiple sclerosis (5.2\%) and Hashimoto's thyroiditis (17.2\%) was retrieved in patients belonging to the PGDM group.

$77.6 \%$ of patients in the PGDM group had a good glycemic compensation at the time of delivery.

Pregnancy disorders

No statistically significant difference were found for the following outcomes: threat of miscarriage, abnormal placental insertion and detachment, amniotic fluid disorders.

However, an association between the threat of abortion and DM2 was found.

The frequency of threatened preterm birth in the PGDM group (24.1\%) was higher than that in the control group (9.5\%; $p$-value: 0.009 ). This difference was more striking when the incidence of preterm delivery was evaluated in DM1 patients (26.2\%, p-value: 0.02$)$.

Pregnancy-induced hypertension and preeclampsia were reported only in the PGDM group. 
Amniotic fluid disorders were only detected in patients with DM1 (12.1\%).

Foetal disorders

Foetal growth disorders were more prevalent in the PGDM group (19\%; p-value $<0.0001)$. Foetal macrosomia (foetal growth $\geq 95^{\circ}$ percentile) was found in foetuses of diabetic mothers ( $p$-value $<$ 0.0001 ), the majority of whom in the DM1 group. An intrauterine growth restriction (foetal growth $<5^{\circ}$ percentile) was found more frequently in in the DM2 group (21.4\%; p-value: 0.02$)$.

Foetal echocardiography was used to investigate cardiac abnormalities more frequently in the PGDM group $(67.4 \%$ VS. $17 \%$; $p$-value $<0.0001)$.

\section{Pregnancy outcomes}

CS delivery was more frequently performed in PGDM patients (87.9\% VS. 52, 44.8\%; p-value <0.0001). This finding was confirmed stratifying by DM (DM1: 90.5\%; DM2: 85.7\%). CS in emergency was more prevalent in the PGDM group (62.8\% VS. 38.5\%; p-value: 0.02$)$.

Frequency of preterm deliveries was higher in the PGDM group (55.2\% VS. $6.0 \%$; p-value $<0.0001)$.

Neonatal outcomes

The median length of hospital stay was 3 days for the births of the control group VS. 11 days for those of the DM1 group ( $p$-value $<0.0001$ ) and 6 for those of the DM 2 group ( $p$-value: 0.0001) (Table 2).

Admission to NICU occurred more frequently in the PGDM group ( $p$-value $<0.0001$ ), with $73.8 \%$ of the births of the DM1 group and $50 \%$ of those of the DM2 group ( $p$-value $<0.0001$ ). Prevalence of respiratory disorders was higher the PGDM group (31\%; $p$-value < 0.0001$)$.

Similarly, RDS occurred more frequently in the PGDM group (29.3\% VS. 5.2\%; p-value < 0.0001 ), as well as neonatal hypoglycemia $(65.5 \%$ VS. $5.2 \%$; p-value $<0.0001)$

Incidence of neonatal jaundice was significantly higher (74.1\%) in the PGDM cohort.

There was a statistically significant difference in birth weight.

Morphological anomalies were detected in $12.1 \%$ and $32.8 \%$ in the control and PGDM group ( $p$-value: 0.001), respectively. 


\section{Discussion}

Diabetic patients had a pregravidic body weight higher than that of the patients in the control group and the median pregravidic BMI differed by 1.7 points between cases and controls. In agreement with other studies [3-8], the increase in pre-pregnancy BMI corresponded to a lower weight gain during pregnancy, probably linked to a greater dietary and behavioral control [14]. However, BMI at delivery was significantly higher in diabetic patients; dietary behavioral control was apparently not sufficient to reverse the differences with the control group. No statistically significant differences were found for: threat of miscarriage, abnormal placental insertion and detachment, amniotic fluid disorders. Higher frequency of threatened preterm births was reported in the PGDM group, confirming the findings of Kong L. et al. [15]. This difference was more evident when preterm delivery was considered in patients with PGDM, explained by spontaneous onset, induction occurred to early schedule childbirth, prevention of maternal and/or fetal complications, reduction of perinatal mortality. The most important causes of preterm childbirth in DM1 could be the uterine overdistension due to fetal macrosomia and/or polyhydramnios. Dollberg et al [16] did not associate the high incidence of preterm childbirth with polyhydramnios, but recognized the role played by genitourinary infections and a history of previous preterm deliveries.

Regarding fetal outcomes, fetal macrosomia was found in the group of cases (12.1\%).

Diabetic patients delivered more frequently by CS [17], with 90.5\% in DM1 patients [17].

No statistically significant differences were found between cases and controls in the use of medical induction of labor with prostaglandins or oxytocin. This is consistent with the fact that diabetic patients are often subjected to elective CS.

LGA infants were more frequently described in DM1 patients $[18,19]$. Another large population-based study in Catalonia [20] found a more prevalent LGA in infants of DM1 mothers. However, no relationship was found with the number of macrosomic fetuses, in line with the literature [21]: the error in the estimation of the fetal weight (10\%-15\%) increases as the gestational age advances, as the fetal weight increases [21].

Morphological abnormalities at birth with diabetes have been documented; in particular congenital heart disease is the outcome most associated with diabetes mellitus [23].

The epidemiology of respiratory disorders at birth seems to partially differ from that of the scientific literature [24-26]. TTN rate was $3.4 \%$ in our cohort VS. $10 \%$ of other studies. The relationship between RDS and PGDM was confirmed in a recent meta-analysis by Yan Li et al. [27]. The incidence of neonatal hypoglycemia was higher in neonates of DM1 mothers $(66.7 \%)[27,28,29]$. The percentage of neonatal jaundice in children of diabetic mothers ranged from $8.7-29 \%[26,27,29]$. Our study showed a higher incidence $(74.1 \%)$, even if those requiring phototherapy were less frequent $(44.8 \%)$.

\section{Strengths And Limitations}


Although the retrospective nature of the study and the selection associated to the enrollment in a reference center may hinder the statistical inference of the findings, the present study shows the epidemiological perspective of an Italian region characterized by a highest incidence of diabetes mellitus in the general population. For this reason, it is of paramount importance to early detect patients at risk to immediately implement preventive measures.

\section{Conclusion}

Patients with PGDM are at increased risk of perinatal and neonatal complications in comparison with pregnant women without PGDM.

\section{Declarations}

Acknowledgments: Ph. Doctor School in Biomedical Sciences, Address in Gender Medicine, Men, Woman and Child, Sassari University, Italy, supported the study

Funding: this research received no external funding

Authors' Contributions: Project development: G.C., A.G.; data collection, manuscript writing/editing: C.C.., F.D. G.S.; Data collection, manuscript editing: G.O., R.A., G.S., G.T. Data collection of newborns: G.O.; project development, data management, manuscript editing: S.D., D.D., M.P.; manuscript writing/editing: G. V., PL.C, L.S., G.S.

\section{Ethics approval and consent to participate}

An ethics approval was not necessary according to the Italian law on observational studies

Conflicts of Interest: The authors report no conflicts of interest.

\section{References}

1. American Diabetes Association. Management of Diabetes in Pregnancy: Standards of Medical Care in Diabetes-2018. Diabetes Care 2018; 41(Suppl 1): S137-S143.

2. Songini M, Muntoni S. High incidence of type 1 diabetes in Sardinia. Lancet 1991; 337: 1047. 
3. Capobianco G, Gulotta A, Tupponi G, Dessole F, Pola M, Virdis G, Petrillo M, Mais V, Olzai G, Antonucci R, Saderi L, Cherchi PL, Dessole S, Sotgiu G. Materno-Fetal and Neonatal Complications of Diabetes in Pregnancy: A Retrospective Study. J Clin Med. 2020 Aug 21;9 (9): 2707. doi: 10.3390/jcm9092707.

4. Shefali AK, Kavitha M, Deepa R, Mohan V. Pregnancy outcomes in pre-gestational and gestational diabetic women in comparison to non-diabetic women: a prospective study in Asian Indian Mothers (CURES-35). J Assoc Physicians India 2006; 54: 613-618.

5. Garne E, Loane M, Dolk H et al. Spectrum of congenital anomalies in pregnancies with pregestational diabetes. Birth Defects Research 2012; 94: 134-140.

6. Parimi M, Nitsch D. A systematic review and meta-analysis of diabetes during pregnancy and congenital genitourinary abnormalities. Kidney Int Rep 2020; 5: 678-693.

7. Agha MM, Glazier RH, Moineddin R, Booth G. Congenital abnormalities in newborns of women with pregestational diabetes: a time-trend analysis, 1994 to 2009. Birth Defects Research 2016; 106: 831839.

8. Fadda GM, Capobianco G, Balata A, Litta P, Ambrosini G, D'Antona D, Cosmi E, Dessole S. Routine second trimester ultrasound screening for prenatal detection of fetal malformations in Sassari University Hospital, Italy: 23 years of experience in 42,256 pregnancies. Eur J Obstet Gynecol Reprod Biol. 2009 Jun;144(2):110-4.

9. Orbain MM, Johnson J, Nance A, Romeo AN, Silver MA, Martinez L, Leen-Mitchell M, Carey JC. Maternal diabetes-related malformations in Utah: A population study of birth prevalence 2001-2016. Birth Defects Res. 2021 Jan 15;113(2):152-160. doi: 10.1002/bdr2.1843. Epub 2020 Nov 23. PMID: 33226174.

10. International Association of Diabetes and Pregnancy Study Groups Consensus Panel, Metzger BE, Gabbe SG, Persson B et al. International association of diabetes and pregnancy study groups recommendations on the diagnosis and classification of hyperglycemia in pregnancy. Diabetes Care 2010; 33(3): 676-82.

11. American Diabetes Association. Diagnosis and classification of diabetes mellitus. Diabetes Care. 2011 Jan;34 Suppl 1(Suppl 1):S62-9. doi: 10.2337/dc11-S062. PMID: 21193628; PMCID: PMC3006051.

12. Royal College of Obstetricians and Gynaecologists. The Investigation and management for the small for gestational age fetus (guidelines 31). London (Royal College of Obstetricians and Gynaecologists). 2002

13. Alexander GR, Himes JH, Kaufman RB, Mor J, Kogan M. A United States reference for fetal growth. Obstet Gynecol 1996; 87: 163-168.

14. Sugiyama T, Nagao K, Metoki H et al. (2014) Japan Diabetes and Pregnancy Study Group. Pregnancy outcomes of gestational diabetes mellitus according to pre-gestational BMI in a retrospective multi-institutional study in Japan. Endocr J. 2014; 61 (4):373 - 80.

15. Kong L, Nilsson IAK, Gissler M, Lavebratt C. Associations of Maternal Diabetes and Body Mass Index With Offspring Birth Weight and Prematurity. JAMA Pediatr. 2019 Apr 1;173(4):371-378. doi: 
10.1001/jamapediatrics.2018.5541. PMID: 30801637; PMCID: PMC6450270.

16. Dollberg S, Bauer R, Lubetzky R, Mimouni FB. A reappraisal of neonatal blood chemistry reference ranges using the Nova M electrodes. Am J Perinatol 2001; 18(8): 433-40.

17. Balsells M, García-Patterson A, Gich I, Corcoy R. Maternal and fetal outcome in women with type 2 versus type 1 diabetes mellitus: a systematic review and metaanalysis. J Clin Endocrinol Metab. 2009 Nov;94(11):4284-91. doi: 10.1210/jc.2009-1231. Epub 2009 Oct 6. PMID: 19808847.

18. Beyerlein A, von Kries R, Hummel M, Lack N, Schiessl B, Giani G, Icks A. Improvement in pregnancyrelated outcomes in the offspring of diabetic mothers in Bavaria, Germany, during 1987-2007. Diabet Med. 2010 Dec;27(12):1379-84. doi: 10.1111/j.1464-5491.2010.03109.x. PMID: 21059090.

19. Mackin ST, Nelson SM, Kerssens JJ, Wood R, Wild S, Colhoun HM, Leese GP, Philip S, Lindsay RS; SDRN Epidemiology Group. Diabetes and pregnancy: national trends over a 15 year period. Diabetologia. 2018 May;61(5):1081-1088. doi: 10.1007/s00125-017-4529-3. Epub 2018 Jan 11. PMID: 29322220; PMCID: PMC6448996.

20. Gortazar L, Goday A, Flores-Le Roux JA, Sarsanedas E, Payà A, Mañé L, Pedro-Botet J, Benaiges D. Trends in prevalence of pre-existing diabetes and perinatal outcomes: a large, population-based study in Catalonia, Spain, 2006-2015. BMJ Open Diabetes Res Care. 2020 Oct;8(1):e001254. doi: 10.1136/bmjdrc-2020-001254. PMID: 33106331; PMCID: PMC7592254.

21. Shub A, Lappas M. Pregestational diabetes in pregnancy: Complications, management, surveillance, and mechanisms of disease-A review. Prenat Diagn. 2020 Aug;40(9):1092-1098. doi: 10.1002/pd.5718. Epub 2020 May 23. PMID: 32333803.

22. Yang GR, Dye TD, Li D. Effects of pre-gestational diabetes mellitus and gestational diabetes mellitus on macrosomia and birth defects in Upstate New York. Diabetes Res Clin Pract. 2019 Sep;155:107811. doi: 10.1016/j.diabres.2019.107811. Epub 2019 Aug 8. PMID: 31401151.

23. Hoang TT, Marengo LK, Mitchell LE, Canfield MA, Agopian AJ. Original Findings and Updated MetaAnalysis for the Association Between Maternal Diabetes and Risk for Congenital Heart Disease Phenotypes. Am J Epidemiol. 2017 Jul 1;186(1):118-128. doi: 10.1093/aje/kwx033. PMID: 28505225; PMCID: PMC5860024.

24. Moosazadeh M, Asemi Z, Lankarani KB et al. Family history of diabetes and the risk of gestational diabetes mellitus in Iran: A systematic review and meta-analysis. Diabetes Metab Syndr 2017; 11 Suppl 1: S99-S104.

25. Kheir AE, Berair R, Gulfan IG, Karrar MZ, Mohammed ZA. Morbidity and mortality amongst infants of diabetic mothers admitted into Soba university hospital, Khartoum, Sudan. Sudan J Paediatr 2012; 12(1): 49-55.

26. M. Al-Qahtani. Infants of Diabetic Mothers: 4 Years Analysis of Neonatal Care Unit in a Teaching Hospital, Saudi Arabia. Saudi Journal of Medicine \& Medical Sciences, 2014; vol. 2, n. 3.

27. Li Y, Wang W, Zhang D. Maternal diabetes mellitus and risk of neonatal respiratory distress syndrome: a meta-analysis. Acta Diabetol. 2019 Jul;56(7):729-740. doi: 10.1007/s00592-01901327-4. Epub 2019 Apr 6. PMID: 30955125. 
28. Riskin A, Itzchaki O, Bader D, lofe A, Toropine A, Riskin-Mashiah S. Perinatal Outcomes in Infants of Mothers with Diabetes in Pregnancy. Isr Med Assoc J. 2020 Sep;22(9):569-575. PMID: 33236556.

29. Xu Q, Lu J, Hu J, Ge Z, Zhu D, Bi Y. Perinatal outcomes in pregnancies complicated by type 1 diabetes mellitus. Gynecol Endocrinol. 2020 Oct;36(10):879-884. doi: 10.1080/09513590.2020.1727432. Epub 2020 Feb 19. PMID: 32075454.

\section{Tables}

Table 1. Anthropometric characteristics of the patients. 


\begin{tabular}{|c|c|c|c|}
\hline & Controls $(n=116)$ & $P G D M(n=58)$ & $p$ value \\
\hline Median (IQR) pregestational weight, kg & $57(50.5-63)$ & $61(55.5-72.5)$ & 0.003 \\
\hline Median (IQR) pregestational BMI, kg/m² & $22(19.8-24)$ & $23.7(20.8-28)$ & 0.005 \\
\hline Normal weight, n (\%) & $93(80.2)$ & $25(52.1)$ & $<0.0001$ \\
\hline Under weight, n (\%) & $7(6.0)$ & $2(4.2)$ & 1.00 \\
\hline Overweight, n (\%) & $14(12.1)$ & $10(20.8)$ & 0.15 \\
\hline Obese, n (\%) & $3(2.6)$ & $8(16.7)$ & 0.001 \\
\hline Median (IQR) weight increase, $\mathrm{kg}$ & $12(10-14)$ & $11(7.5-14)$ & ns \\
\hline Excessive weight increase (>12 kg), n (\%) & $44(37.9)$ & 19 (39.6) & ns \\
\hline Median (IQR) weight at delivery, kg & $70(63-75)$ & $74(65-85)$ & 0.01 \\
\hline \multirow[t]{2}{*}{ Median (IQR) BMI at delivery, $\mathrm{kg} / \mathrm{m}^{2}$} & $26.6(24.8-28.8)$ & $27.9(25.7-32.2)$ & 0.02 \\
\hline & Controls $(n=116)$ & $D M 1(n=42)$ & $p$ value \\
\hline Median (IQR) pregestational weight, kg & $57(50.5-63)$ & $60(55-68)$ & 0.04 \\
\hline Median (IQR) pregestational BMI, $\mathrm{kg} / \mathrm{m}^{2}$ & $22(19.8-24)$ & $23.7(20.8-25.9)$ & 0.01 \\
\hline Normal weight, n (\%) & $93(80.2)$ & $20(58.8)$ & 0.02 \\
\hline Under weight, n (\%) & $7(6.0)$ & $0(0.0)$ & ns \\
\hline Overweight, n (\%) & $14(12.1)$ & $8(23.5)$ & ns \\
\hline Obese, n (\%) & $3(2.6)$ & $3(8.8)$ & ns \\
\hline Median (IQR) weight increase, $\mathrm{kg}$ & $12(10-14)$ & $11.5(9-13)$ & ns \\
\hline Excessive weight increase (>12 kg), n (\%) & $44(37.9)$ & $14(41.2)$ & ns \\
\hline Median (IQR) weight at delivery, kg & $70(63-75)$ & $73(65-80)$ & ns \\
\hline \multirow[t]{2}{*}{ Median (IQR) BMI at delivery, $\mathrm{kg} / \mathrm{m}^{2}$} & $26.6(24.8-28.8)$ & $27.8(25.8-30.1)$ & ns \\
\hline & Controls $(n=116)$ & $D M 2(n=14)$ & $p$ value \\
\hline Median (IQR) pregestational weight, kg & $57(50.5-63.0)$ & $76(55.5-83.5)$ & 0.009 \\
\hline Median (IQR) pregestational BMI, $\mathrm{kg} / \mathrm{m}^{2}$ & $22.0(19.8-24.0)$ & $28.2(21.2-32.9)$ & 0.03 \\
\hline Normal weight, n (\%) & $93(80.2)$ & $3(25.0)$ & $<0.0001$ \\
\hline Under weight, n (\%) & $7(6.0)$ & $2(16.7)$ & ns \\
\hline Overweight, n (\%) & $14(12.1)$ & $2(16.7)$ & ns \\
\hline Obese, n (\%) & $3(2.6)$ & $5(41.7)$ & $<0.0001$ \\
\hline Median (IQR) weight increase, kg & $12(10-14)$ & $11(6-15.5)$ & ns \\
\hline Excessive weight increase (>12 kg), n (\%) & $44(37.9)$ & $4(33.3)$ & ns \\
\hline Median (IQR) weight at delivery, kg & $70(63-75)$ & $84.5(65.0-92.5)$ & 0.02 \\
\hline Median (IQR) BMI at delivery, $\mathrm{kg} / \mathrm{m}^{2}$ & $26.6(24.8-28.8)$ & $30.6(25.1-37.1)$ & ns \\
\hline
\end{tabular}

Pregestational diabetes mellitus (PGDM); Diabetes Mellitus type 1 (DM1); Diabetes Mellitus Type 2 (DM2); Normal weight (BMI between 18 and $\left.24.9 \mathrm{~kg} / \mathrm{m}^{2}\right)$; under weight $\left(\mathrm{BMI}<18 \mathrm{~kg} / \mathrm{m}^{2}\right)$; overweight (BMI between 25 and $\left.29.9 \mathrm{~kg} / \mathrm{m}^{2}\right)$; obese (BMI $\left.\geq 30 \mathrm{~kg} / \mathrm{m}^{2}\right)$.

Table 2. Neonatal outcomes. 


\begin{tabular}{|c|c|c|c|}
\hline & Controls $(n=116)$ & $P G D M(n=58)$ & $p$-value \\
\hline Fetus appropriate for gestational age (AGA) n (\%) & $96(82.8)$ & $27(46.6)$ & $<0.0001$ \\
\hline Fetus small for gestational age (SGA) n (\%) & $12(10.3)$ & $4(6.9)$ & ns \\
\hline Fetus large for gestational age (LGA) n (\%) & $8(6.9)$ & $27(46.5)$ & $<0.0001$ \\
\hline Respiratory disorders n (\%) & $11(9.5)$ & $18(31.0)$ & $<0.0001$ \\
\hline RDS (Respiratory Distress Syndrome) n (\%) & $6(5.2)$ & $17(29.3)$ & $<0.0001$ \\
\hline TTN (Neonatal transient tachypnea) n (\%) & $2(1.7)$ & $2(3.5)$ & ns \\
\hline Neonatal intubation n (\%) & $4(3.5)$ & $6(10.3)$ & ns \\
\hline Median (IQR) glycemia at $3^{\circ}$ hours,mg/dl & $66.5(60-73.5)$ & $58.5(37-72)$ & 0.003 \\
\hline Median (IQR) lower glycemia, mg/dl & $61.9(14.2)$ & $40.3(17.0)$ & $<0.0001$ \\
\hline Neonatal hypoglycemia n (\%) & $6(5.2)$ & $38(65.5)$ & $<0.0001$ \\
\hline Neonatal jaundice n (\%) & $29(25.0)$ & $43(74.1)$ & $<0.0001$ \\
\hline Phototherapy n (\%) & $14(12.1)$ & $26(44.8)$ & $<0.0001$ \\
\hline \multirow[t]{2}{*}{ Morphological anomalies n (\%) } & $16(13.8)$ & $19(32.8)$ & 0.003 \\
\hline & Controls $(n=116)$ & $D M 1(n=42)$ & p-value \\
\hline Fetus appropriate for gestational age (AGA) n (\%) & $96(82.8)$ & $17(40.5)$ & $<0.0001$ \\
\hline Fetus small for gestational age (SGA) n (\%) & $12(10.3)$ & $1(2.4)$ & ns \\
\hline Fetus large for gestational age (LGA) n (\%) & $8(6.9)$ & $24(57.1)$ & $<0.0001$ \\
\hline Respiratory disorders n (\%) & $11(9.5)$ & $15(35.7)$ & $<0.0001$ \\
\hline RDS (Respiratory Distress Syndrome) n (\%) & $6(5.2)$ & $14(33.3)$ & $<0.0001$ \\
\hline TTN (Neonatal transient tachypnea) n (\%) & $2(1.7)$ & $2(4.8)$ & ns \\
\hline Neonatal intubation n (\%) & $4(3.5)$ & $6(14.3)$ & 0.02 \\
\hline Median (IQR) glycemia at $3^{\circ}$ hours,mg/dl & $66.5(60-63.5)$ & $58(37-76)$ & 0.02 \\
\hline Median (IQR) lower glycemia, mg/dl & $61.9(14.2)$ & $40.2(18.1)$ & $<0.0001$ \\
\hline Neonatal hypoglycemia n (\%) & $6(5.2)$ & $28(66.7)$ & $<0.0001$ \\
\hline Neonatal jaundice $\mathrm{n}(\%)$ & $29(25.0)$ & $43(74.1)$ & $<0.0001$ \\
\hline Phototherapy n (\%) & $14(12.1)$ & $26(44.8)$ & $<0.0001$ \\
\hline \multirow[t]{2}{*}{ Morphological anomalies n (\%) } & $16(13.8)$ & $16(38.1)$ & 0.001 \\
\hline & Controls $(n=116)$ & $D M 2(n=14)$ & $p$-value \\
\hline Fetus appropriate for gestational age (AGA) n (\%) & $96(82.8)$ & $8(57.1)$ & 0.04 \\
\hline Fetus small for gestational age (SGA) n (\%) & $12(10.3)$ & $3(21.4)$ & ns \\
\hline Fetus large for gestational age (LGA) n (\%) & $8(6.9)$ & $3(21.4)$ & ns \\
\hline Respiratory disorders n (\%) & $11(9.5)$ & $3(21.4)$ & ns \\
\hline RDS (Respiratory Distress Syndrome) n (\%) & $6(5.2)$ & $3(21.4)$ & ns \\
\hline TTN (Neonatal transient tachypnea) n (\%) & $2(1.7)$ & $0(0.0)$ & ns \\
\hline Neonatal intubation n (\%) & $4(3.5)$ & $0(0.0)$ & ns \\
\hline Median (IQR) glycemia at $3^{\circ}$ hours,mg/dl & $66.5(60-63.5)$ & $53(37-67)$ & 0.003 \\
\hline Median (IQR) lower glycemia, mg/dl & $61.9(14.2)$ & $41.1(13.4)$ & $<0.0001$ \\
\hline
\end{tabular}




\begin{tabular}{lccc} 
Neonatal hypoglycemia n (\%) & $6(5.2)$ & $9(64.3)$ & $<0.0001$ \\
\hline Neonatal jaundice n (\%) & $29(25.0)$ & $9(64.3)$ & 0.002 \\
\hline Phototherapy n (\%) & $14(12.1)$ & $4(28.6)$ & ns \\
\hline Morphological anomalies n (\%) & $16(13.8)$ & $2(14.3)$ & ns \\
\hline
\end{tabular}

